\title{
An Empirical Analysis on the Identification of Deep Link Infringement: Take the Judgment Documents of the Chinese Courts in the Past Ten Years as Analysis Samples
}

\author{
Mao Rui \\ School of Law, Jiangsu University, Zhenjiang, China
}

Email address:

446796318@qq.com

To cite this article:

Mao Rui. An Empirical Analysis on the Identification of Deep Link Infringement: Take the Judgment Documents of the Chinese Courts in the Past Ten Years as Analysis Samples. International Journal of Law and Society. Vol. 4, No. 1, 2021, pp. 54-60. doi: 10.11648/j.ijls.20210401.17

Received: March 8, 2021; Accepted: March 18, 2021; Published: March 26, 2021

\begin{abstract}
In the era of infringement 3.0, deep linking has become a typical behavior of network communication, and disputes frequently occur. However, since its inception, deep linking has always been in a gray area between legal and illegal, causing the court to find itself in a dilemma in determining the infringement of deep linking. Therefore Clarifying the related issues of deep link infringement determination should be the proper meaning of advancing copyright protection in China. Through the case analysis and empirical research on the judgment documents of Chinese courts in the past ten years, we can understand the basic situation of its legal regulations, including the geographical distribution, time distribution, and right object distribution of judgment documents. Then sort out that in judicial practice the identification standards for deep link infringements have not been unified, the space for indirect infringements is insufficient, complexity of consideration factors of trial results, and the evaluation of mixed technicality for difficult problems related to the evaluation of technology use behavior. Finally, it is suggested that "providing works" should be used as the identification standard, to clarify the legal rights basis of the works of the chained party, to improve the burden of proof by the parties to the deep link, and to improve the scientific system for identifying infringements of the deep link.
\end{abstract}

Keywords: Deep Linking, Right of Information Network Communication, Providing Works

\section{Introduction}

The development of Internet technology promotes the innovation of information dissemination mode, which mainly changes from traditional replication communication to digital technology communication. Among them, the deep link can lead to no web page Jump, and directly display the results of the works of the chained party on the chained party's website. Users can obtain the works without visiting the web page or client of the chained party, so that the transmission interests of the chained party, such as the click through rate, traffic income, advertising income, etc., are transferred to the chained party, which leads to the academic debate on whether it infringes the information network communication right of the chained party. In recent years, the discussion on the nature of deep links has been a hot topic in academic research, and the identification of deep link infringements affects the scope of application of the right of information network dissemination.
Since the 2001 "Copyright Law" clearly stipulated the "information network dissemination right", this type of dispute has become the most important type of case in copyright and even intellectual property disputes [1].

This paper is based on the empirical research and case analysis of court judgment documents in China in recent ten years. It explores the current situation of deep link infringement identification in current judicial practice, and examines the complex relationship between the specific standards of identification and deep link behavior.

\section{The Basic Situation of Deep Link Judgment Documents}

Using the infringement of information network 
dissemination rights and deep links as keywords, we searched the Chinese judicial documents online, and found 793 judicial documents from 2010 to 2020 . Including all the documents that the parties claim to belong to deep links but are not actually related to deep links, and the contract terms involve deep links but the actual behavior has nothing to do with deep links. After studying the content of the judgments one by one, 656 judgments and repeated cases that have nothing to do with the content of the deep link are eliminated. Finally, the total number of effective samples used in the empirical analysis of this paper is 137 .

In terms of geographic distribution, cases involving deep link infringement identification are mainly concentrated in Beijing (45/137), Guangdong Province (27/137), Shanghai (26/137), Zhejiang City (27/137), Jiangsu Province (9/137). This is consistent with the spatial distribution law that China has always shown in copyright litigation [2]. The reason is that, on the one hand, civil disputes involving the infringement of information network dissemination rights are under the jurisdiction of the people's court at the place of infringement or where the defendant is domiciled. Most of the parties who set up deep links are Internet companies, mostly in the eastern coastal and economically developed provinces. On the other hand, there are currently special courts for intellectual property rights in Beijing, Shanghai, and Guangzhou, and 20 intellectual property courts in 17 provinces including Jiangsu and Zhejiang to facilitate the parties to protect their legitimate rights and interests through legal means. Therefore, the problems presented by the judgment documents based on this article can also reflect the needs of judicial practice.

Since the launch of the "Sword Net Action" to combat online infringement and piracy in 2010, in the intellectual property cases accepted by Chinese courts, the number of disputes over the right to disseminate information on the Internet has shown a rapid growth trend [1]. As can be seen from the figure above, the number of deep link cases has been almost stable at about 15 since 2012. The state attaches importance to network copyright. As a typical case of infringing the right of information network communication, deep link behavior has always been the focus of regulation. What kind of copyright law evaluation should be given is also one of the most important issues in the current judicial field.

From the perspective of the distribution of rights objects, judgment documents involving film works and similar electronic works are the most, with 124 pieces, accounting for about 90\% (124/137), followed by judgment documents involving writing works, with 9 pieces, accounting for approximately $7 \%$ (9/137). According to the new "Copyright Law" approved at the 23rd meeting of the 13th National People's Congress Standing Committee on November 11, 2020, all "movie works or works created in a similar way to movies" are changed to "audiovisual works", in response to the need to strengthen the copyright protection of the network entertainment industry in the new era. The judicial practice should also pay attention to the judgment rules of audio-visual works. Empirical research shows that in addition to film works, works involving deep links also include short videos, online games, sports events, various programs and other new audio-visual works. Therefore, this article's research on the identification of deep link infringement is one of the core issues of online copyright protection, and may provide practical reference for the copyright protection of audiovisual works.

\section{The Practical Dilemma of Deep Link Infringement Determination}

The identification of deep link infringement is difficult in practice, mainly due to the enumeration of information network dissemination rights and the legal provisions that have blurred the understanding of copyright boundaries to a certain extent. Based on the inherent limitations of legislation, only by exploring the specific content of infringement dispute judgments and clarifying the specific identification boundaries of deep links, can we build a more effective scientific identification system.

\subsection{Identification Standards Have Not Yet Been Unified}

Chinese scholars and judges have proposed server standards, substantive replacement standards, user perception standards and other theoretical viewpoints on the determination of the nature of deep link behavior. The core of the server standard is to judge whether it constitutes uploading works to a server that is open to the public where the chain is set up; user perception The standard emphasizes the user's personal subjective feelings to determine who provides the work; the substantive replacement standard focuses on replacing the chained website to provide the broadcast source; the new public standard refers to the generation of network users beyond the scope of the original.

Statistics on the standards for identifying the nature of deep links show that empirical research shows that the current judicial practice in China mainly adopts server standards for identifying deep links, accounting for 89.8\% (123/137). Only a few courts apply substantive alternative standards, user perception standards, and new public standards in the trial process. The reason for this is that the user perception standard is completely separated from the determination of objective facts and is based on the user's subjective cognition. However, users cannot have a completely consistent level of network cognition. It is very likely that even when the evidence in the case is exactly the same, In view of the same fact, different users are likely to come to different conclusions, and in some cases, the deep link itself presents a more complex form, such as Beijing Zhongqingwen Culture Media Co., Ltd. and Beijing Baidu Netcom Technology Co., Ltd. infringed on the work information network In the case of dissemination rights dispute, the full address displayed by the deep link is more complicated, including both the URL of Baidu and the URL of the source website. In addition to the substantive replacement standard based on the subjective feelings of users, the criterion for judging whether to replace the chained party to provide works is whether the two parties benefit or harm. If the deep 
linking behavior causes the chained party to intercept the chained party's users, click-through rate, etc. If the copyright benefit is damaged, it can be deemed as infringement of the right of information network dissemination. The standard skips the determination of the legitimacy of the behavior, the result only theory confuses the responsibility determination and the infringement determination. The new public standard was pioneered by the European Court of Justice, emphasizing whether the number of audiences has increased, focusing on the control of the scope of dissemination, and thus settled on the judgment of the number of Internet users. The standard has changed from centering on authors and behaviors to centering on users, and has not yet been recognized by academics.

The server standard comes from the relevant provisions of the "World Intellectual Property Organization Copyright Convention" (WCT). Article 3 of the newly revised "Regulations of the Supreme People's Court on Several Issues Concerning the Applicable Law for the Trial of Civil Disputes concerning the Infringement of Information Network Dissemination Rights" in 2020 remains The server standards are not clearly stated. In the early stage of network infringement characterized by "uploading to its own server", the "server standard" has indeed played a key guiding role in determining the infringement of information network transmission rights [3]. However, empirical studies have shown that judicial practice has given an affirmative answer to whether "placement in an information network" should be understood as being placed on a server, which is the most widely applicable. However, during the trial process, the server standards still did not consider the nature of "providing works", and characterized deep links as only a positioning tool in cyberspace, rather than an act of information network dissemination. Therefore, in order to regulate deep linking, the court analyzes the comprehensive argument of other behaviors on top of the server standard. It can be seen that after the emergence of new technical means, Chinese courts will expand the interpretation of existing standards or seek more suitable standards to determine the scope of deep linking. However, the problems that exist in this way are obvious. On the one hand, how to proceed Legal interpretation to compare the superiority of various identification standards makes the identification of the nature of deep links more complicated, and the operation invisibly increases the judicial cost. The most direct basis for determining whether the behavior of deep linking as a specific behavior involved in the case belongs to the behavior of information network communication is still the behavior of "providing works"[4]. On the other hand, deep linking has become a typified case. The Chinese court's determination standards should not arbitrarily make breakthroughs, and a strict and systematic infringement determination standard system should be established.

\subsection{Insufficient Space for Indirect Infringement}

Introducing the concept of indirect infringement can characterize deep linking as joint infringement, but the indirect infringement liability of the chain-setting party needs to be based on direct infringement, and at the same time, it is necessary to prove that the chain-setting party is at fault [5]. From the perspective of judicial practice, direct infringement and non-infringement are the main judgment results, of which direct infringement accounts for $77.4 \%$ (106/137), and indirect infringement accounts for $8.7 \%(12 / 137)$, showing the use of indirect infringement is insufficient. The reason is that, on the one hand, the right holder tends to claim direct infringement by the party that establishes the chain. If the right holder directly pursues the infringement of the information network dissemination right by the chaining party, he only needs to provide preliminary proof of the actual work provided, and the chaining party shall bear the burden of proof. If the chaining party cannot provide any valid evidence to prove that the infringing works involved are provided by a third party, It is believed that by providing works, they have carried out acts that infringe on the spread of information on the Internet. For example, in the case of Hangzhou Alibaba Technology Co., Ltd. and Shanghai Xuanting Entertainment Information Technology Co., Ltd. for infringement of the right to disseminate information on the network, the Chinese court held that if Alibaba failed to prove that the work involved was not provided by it and placed on the Internet, it should It is presumed that Alibaba has implemented information network communication behavior. On the contrary, if it is claimed to constitute indirect infringement, it is necessary to prove fault, and the burden of proof on the right holder is relatively higher. Therefore, it is more conducive to protect the legitimate rights and interests of the obligee to claim that the accused deep link behavior constitutes direct infringement.

On the other hand, indirect infringement requires direct infringement as a prerequisite, that is, only the chained party is the direct infringer or the party providing the work is the direct infringer. In this case, the deep linking behavior constitutes aiding infringement. However, in most cases, the chained party and the party who provided the work are the legal acquirers of the work, and there is no third party who directly infringes the work. The Chinese courts are more inclined to determine that the act of setting up deep links to provide online display works directly infringes the right holder's information network dissemination right.

\subsection{Complicated Considerations in the Trial Results}

In the past, server standards occupies the mainstream status, which is related to the background of China's vigorous support for the development of network technology. The adoption of server standards can make the determination of infringement relatively tolerant, and thus tends to exempt from liability for acts of setting up links on the Internet that infringe on the right of communication on the information network. Moreover, according to the "Server Standard", deep link behavior can only be the help behavior of information network communication behavior, and it is an indirect infringement [6]. However, now the server standard is still the mainstream standard, which does not match with the result of judging infringement: the server standard accounts for the mainstream and direct infringement accounts for the largest proportion. 
The result of the judgment shows that the considerations of the deep link infringement determination process are complicated. In addition to the server standard determination standard as the standard for determining whether the infringement is infringement, there are also many other influencing factors. Practice demands call for the establishment of more systematic identification standards, and the single use of technical standard division has not touched the core elements of the identification process. The following summarizes several specific cognizance factors and disputes in practice.

First of all, judicial practice also focuses on investigating whether the chained party has a legal source and whether there is a restrictive authorization. If the linked content belongs to authorized legal content, it is difficult for the Chinese court to support the right holder's claim that the chaining party infringes the information network dissemination right. In addition, even if it has a legitimate source, the results of the adjudication show different infringement patterns based on specific facts such as restrictive authorization, and there are disputes in the same case. For example: In the case of Shenzhen Xunlei Network Technology Co., Ltd. and Beijing Hualu Northern Electronics Co., Ltd. over infringement of the right to disseminate information on the network, The Chinese court held that the film linked to Hualu N1 player was provided by a third-party video website authorized by Shenzhen Xunlei company, the defendant Beijing Hualu Company has no subjective fault, and its actions involved in the case do not constitute an infringement of the plaintiff's Shenzhen Xunlei Company's information network dissemination rights. It holds the view that the plaintiff's rights are exhausted after he has obtained legal authorization as the obligee. In the case of Beijing Lenovo FM Technology Co., Ltd. (hereinafter referred to as "Lenovo FM Company") and LeTV (Tianjin) Information Technology Co., Ltd. in a dispute over infringement of the right to disseminate information on the work information network, the court of first instance held that the provider of the work, Feihu Company, was involved in the work Obtain legal authorization and sign a promotion agreement with Lenovo FM, but if it exceeds the form stipulated in the promotion agreement, it shall be deemed to have violated the right holder's information network dissemination right. The court of second instance held that if the software involved in the case needs to play the works involved in the case normally, Feihu must provide the corresponding server port excuse password. Therefore, the deep link does not constitute the provision of works and does not constitute an infringement of the right of information network dissemination. Therefore, whether the chained party has a legal source still needs to be further judged. In general, The Chinese court held that the deep link established by the chaining party and the chained party for restrictive authorized content constitutes an infringement of the right to spread the information of the works involved in the case. However, when the chain parties do not have a common intentional expression, it may only involve the simple breach of contract by the chained party.

Secondly, whether it is an active directional link, whether it can control the content of the work, and whether it is inductive. A large number of directional links are mentioned in the judgment documents, and they are considered not only technical support, but also processing of the content. If the chain party provides targeted search services that induce users to obtain works or can upload, modify, or delete information, and delete advertisements that only link to the main content, it can be determined that it has provided works and directly implemented information network dissemination behavior. For example, in the case of Shanghai Qianshan Network Technology Development Co., Ltd. (hereinafter referred to as "Qianshan Company") and Zhejiang Radio and Television Group infringing on the right to disseminate information on the work's network, Qianshan Company carried out an investigation on the videos aggregated on the "TV Cat Video" platform. Summarizing, editing, and collating are not automatic technical links but artificial control links, which are beyond the scope of link services, resulting in the spreading range beyond the control of the chained party, and damaging the chained party's right to spread information on the network.

\subsection{Mixed Technical Evaluation and Evaluation of Technology Use Behavior}

Due to the technical factors involved in deep linking behavior, the process of infringement determination often considers whether the deep link is cracked or not. This kind of identification method is applied in practice in many judgments, However, the actual cracking technology can not constitute the standard to determine the infringement of the right of information network communication, and Chinese majority court have not determined the infringement in the name of technical protection measures. However, some courts directly used the relevant provisions of Article 4 of the Regulations on the Protection of the Right to Dissemination of Information Networks to believe that deep link infringement, and confuse the determination of deep link infringement with technical evaluationn. For example, in the dispute over intellectual property rights and infringement between Shenzhen Chongde Animation Co., Ltd. and Beijing Aiqiyi Technology Co., Ltd., The Chinese court held that the defendant's act of stealing the link of CCTV cartoon involved in the case was to set up a deep link for the linked website under the condition of destroying the technical measures, and the defendant bypassed the forbidden chain measures taken by the linked website, which belonged to the act of destroying the technical measures expressly prohibited in Article 4 of the regulations on the protection of the right of information network communication, and constituted a violation of the plaintiff's information network communication of cartoon involved in the case The direct infringement of the right. If the disputes are dealt with in a way that destroys technical measures, avoids the essential nature of deep links, and turns the issue of fact determination into a problem of technical review and judgment, it is obviously also suspected of avoiding the more important [7]. At present, it is urgent to get rid of the misunderstanding of link services, and the use of link technology cannot be used as a necessary and sufficient condition for identifying link 
services, that is, link behavior cannot be equated with link services [8]. This paper holds that it is not suitable to make a single cut provision for the behavior of avoiding technical measures, and also to stipulate the behavior of avoiding technical measures as independent infringement form. Technical evaluation is static, and the evaluation of technology usage behavior is dynamic. Combined with the rapid increase of mobile phone usage rate, there is no obvious steps such as opening new pages and loading in the process of page Jump. The process is more and more inconspicuous, that is, software switching unmarked nodes. It is difficult to make accurate judgment only from technical considerations, and it is not possible to determine that deep links are equivalent to providing works according to technical results. It is also necessary to combine the specific work situation, the situation of technical measures and the purpose and means of avoiding behavior, that is, comprehensive analysis is made from all aspects of the behavior of technology use.

\section{Reconstruction of the Thinking on Deep Link Infringement}

Based on the deep link of the judicial practice of the current situation, the demand and the plight of the analysis. This article believes that the thinking of deep link infringement identification needs to be adjusted accordingly to adapt to the complex real communication environment of the new era. Take the legal value concept contained in the server standard and the profit distribution mechanism behind the network link behavior as the research perspective [10]. The problems in practice are raised to the theoretical level for discussion, and the scientific argumentation ideas of how chain creators transform from network service providers to work providers are constructed in order to balance the interests of rights holders, the public, and network services.

\section{1. "Providing Works" as the Standard}

With the development of Internet and the innovation of technology, the specific practice forms of deep link behavior are constantly changing, which leads to the complexity of tort and legal issues of deep link. The limitations of various identification standards have been mentioned above, but the current mainstream practice of judicial adjudication still adheres to server standards, while advocating a legal interpretation of "the act of providing works to the public" and explaining the connotation and extension of the act of provision based on specific facts. Recognizing "providing works" is the key to distinguishing linking behavior from linking services. This kind of judging thinking and practice shows that the identification standard that advocates providing works on open servers only constitutes one of the manifestations of the act of providing works to the public. Professor Liu Yinliang also pointed out that the server standard is only a sufficient condition for providing works to the public, not a necessary condition [11]. The legal text of China's "Copyright Law" does not stipulate server standards, and various identification standards are the interpretation of "acts of providing works", which belong to the category of interpretive theory. In other words, various identification standards are only principles for judging the properties of deep link behavior itself. Some scholars believe that only on the premise of clarifying the legal attributes of the conduct can it be further determined whether the conduct constitutes infringement [12]. This article supports this point of view, but when it comes to the infringement determination of deep links, on the one hand, after determining the nature of the behavior, and then determining its infringement, in the final analysis, it is inseparable from the analysis of the fact that "provides the work". Judgment is not the only influence on the determination of infringement; On the other hand, from the change of the interpretation of the server standard, it is the essence of infringing the right of information network communication to always grasp the behavior of providing works to the public without authorization, that is, the core standard should be the return behavior itself, with "providing works" as the standard. Rather than seeking a new path and lacking a basis for argumentation, it is better to return to the essence. This is the most interpretive and operational standard extracted in practice. It can also enable judicial judgments to obtain stable expectations, and be forward-looking and open.

\subsection{Clarify the Legal Rights Basis of the Chained Party's Work}

We should classify the network service provision behavior of network service providers. Different types of network service provision behaviors should be treated differently when assuming responsibilities due to different situations involving external links and deep links [13]. Some scholars have put forward the thinking of regulating network linking behavior: on the basis of distinguishing the two effects of "promoting the proliferation of piracy" and "providing technical convenience" that the network chaining platform may play, the two types of legal upload works and illegal upload works are regulated respectively [9]. The deep linking behavior also belongs to the network linking behavior, which has the positive and convenient effect of linking technology and the negative infringement risk of harming the interests of copyright owners. In short, on the one hand, if the chained work is legal, the chaining party also has a legal source, allowing deep linking behavior to meet the demands of forgiving use in the network environment. On the other hand, if the chaining party induces a large number of illegal works Uploading and constituting a substantive act of providing works, then it is beyond reproach to determine that the act of deep linking infringes the right of information network communication of the right holder. Therefore, this article believes that under the premise of insisting on "providing works" as the standard for determining infringement of deep linking behavior, the legal rights basis of the chained party's works should also be clarified in the complex behavior composition, that is, to distinguish the different types of the chained party's works. The focus of attention in the process of identifying is the deep link behavior. 
The legal rights basis of the chained party's work is used as an auxiliary identification factor, covering a variety of situations. According to the above analysis, the proposal is divided into two levels: 1 . whether there is a legal source. It includes whether to obtain the legal authorization of the copyright owner, and whether it belongs to the restrictive authority, that is, whether to agree on the in-depth link; 2. Whether it can be spread freely. Whether the linked website takes technical protection measures or provides open ports. In the process of judging the act of "providing works", the eyes shuttle back and forth between these two levels. The specific facts in different situations will lead to different factual patterns, and then in different patterns, they will be identified according to the special facts of the case and the requirements of different burden of proof.

\subsection{Improve the Burden of Proof for Deep Linking Behavior}

The determination of the infringement of deep linking activities must ultimately be implemented in the issue of evidence. The core of deep linking is still linking. Its main proof obstacles come from the development of technology and technique, Including the emergence of mobile phone terminal and pad terminal, as well as the difficulty of proof for fault, and even encounter difficulties that can not be identified. Therefore, to improve the burden of proof for deep linking behavior is to fully consider the obstacles to proof in the distribution of the burden of proof, that is, the issue of the right holder's ability to produce evidence. On the one hand, in determining the direct infringement of deep links, it reduces the difficulty of proof for the right holder to provide preliminary evidence, so as to transfer the burden of proof to the accused infringing party. Confirm the legal validity and probative power of evidence obtained by electronic deposit, electronic data, blockchain technology and other methods. At the same time, a special network evidence admissibility agency was established. The copyright owner collects evidence by entrusting the admissibility agency recognized by the court, which not only protects the integrity and authenticity of the evidence, but also significantly reduces the burden on the right owner to provide evidence [14]. For the chaining party, the easy-to-set text display effect such as the watermark displayed on the video screen or the source of the graphic display cannot prove that the chaining party is only providing the link behavior, but should be carefully judged based on the specific behavior facts.

On the other hand, in determining the indirect infringement of deep links, in view of the insufficient application space for indirect infringement, it is recommended to reduce the responsibility of the right holder to prove the subjective fault of the chaining party. For chain establishment parties, a higher duty of care should be imposed, and the "red flag principle" should be strictly applied. This requires the court to be more rigorous, strengthen the application of laws and regulations related to the presumption of "knowledge" and "should know", and summarize the specific behaviors of typical deep links in practice into the category of presumption of fault. For example, if you select, edit, organize, or recommend the content of the work through the deep link directed search, directed link to the linked webpage or client, or the linked party apparently provides the work without permission, it can be deemed to have an obvious subjective fault.

\section{Conclusion}

In the context of strengthening copyright protection in the country, in the current legal framework system, it is difficult to find the legal provisions that can be directly applied to the identification of deep link infringement. The determination of attributes such as server standards should not be the standard for judging whether deep linking constitutes infringement, or even is the only standard. Deep links have important commercial interests to the copyright owner and should fall within the scope of the copyright owner's exclusive rights. [15] Nowadays, it is no longer blindly seeking to create a relaxed environment for domestic websites. Deep links should be regulated and judicial protection of copyright should be strengthened. On the basis of such value judgments, it is necessary to seek the standard and unification of the application of the law. The judicial organs should change the thinking of the trial and form a unified judgment standard: return to the judgment of the nature of the "provided work" and clarify whether the chained party's work has obtained legal authorization, Whether to agree on restrictive powers, whether to set up technical protection measures, and reduce the burden of proof of the right holder, strictly apply the "red flag principle. Protect the legitimate interests of the right holder through the reconstruction of the deep link infringement identification idea, and promote the construction of national legality, and then promote the realization of China's innovation-driven development strategy.

\section{Project}

Postgraduate Research \& Practice Innovation Program of Jiangsu Province, Project Name: Judicial Empirical Research On the Constitution of Network Communication Behavior -Taking the Cases in Recent Ten Years as the Scope, Project Number: SJCX20_1393.

\section{References}

[1] Feng Gang. Research on Disputes of Infringement of Information Network Dissemination Rights Involving Deep Links [J]. Intellectual property, 2016, (08): 20-28.

[2] Zhang Jian. An Empirical Analysis of Copyright Dispute Litigation in Recent Ten Years [J]. China Publishing Journal, 2014, (04): 36-39.

[3] Huang Hui, Liu Jiahui. Reasonable allocation of liability for copyright infringement of deep links on network aggregation platforms [J]. Contemporary Law Review, 2019, 33 (04): 39-49.

[4] $\mathrm{Xu}$ Minchau. On the Definition of the Act of "Providing Works" on the Internet [J]. Peking University Law Journal, 2020, 32 (02): 378-401. 
[5] Wang Qian. On the Legal Nature and Regulation of the Act of Providing "Deep Links" [J]. Law Science, 2016, (10): 23-39.

[6] Mo Hongxian, Liu Zhihan. Research on Legal Evaluation of Deep Linking Behavior [J]. Journal of Shanxi University (Philosophy and Social Science Edition), 2018, 41 (03): 114-118.

[7] Yang Xingfang. Legal Regulation of Linking Behavior in the Dissemination of TV Programs-A Case Study of the Copyright Protection Case of "Bite of China" [J]. TV Research, 2020, (05): 59-61.

[8] Zhao Junmei. The legal application of deep linking of aggregation platforms [J]. Journal of Law Application, 2019, (15): 74-82.

[9] Liu Yinliang. On the Limitations of Server Standards [J]. Law Science Magazine, 2018, 39 (05): 57-69.

[10] Xie Lanfang, Fu Qiang. Discussion on the Judgment Standar-d of Infringement of Deep Linking Behavior [J]. Intellectual Property, 2016, (11): 41-45.
[11] Zhang Peng. Thinking and Means of Regulating Internet Linking Behavior [J]. ECUPL Journal, 2018, 21 (01): 37-49.

[12] Hong Liou, Jiang Yike. On the Legitimacy of Server Standards for the Right of Information Network Communication [J]. University Publishing, 2019, (04): 56-59.

[13] He Lianhong, Yin Qin. Rethinking on the Legal Nature of Deep Linking of Works [J]. Journal of Gansu Political Science and Law Institute, 2019, (06): 20-36.

[14] Wang Heyun, Xu Jialei. On the Legal Regulation of Deep Links in Video Aggregation APP [J]. China Publishing Journal, 2019, (07): 51-55.

[15] Wan Yong. Rethinking and Reconstructing the Theory of Legal Regulation of Deep Links [J]. Science of Law (Journal of Northwest University of Political Science and Law), 2020, 38 (01): 36-45. 